\title{
Anatomía de la madera de cinco especies de la familia Rosaceae
}

\section{Wood anatomy of five specie of the Rosaceae family}

\author{
Carmen de la Paz Pérez Olvera ${ }^{1}$, Mariana Mendoza Aguirre ${ }^{1}$, \\ Jacqueline Ceja Romero ${ }^{1}$ y Leticia Pacheco ${ }^{1}$
}

\section{RESUMEN}

Se presenta la descripción anatómica, de tipo macroscópica y microscópica de la madera de cinco especies de frutales que pertenecen a la familia Rosaceae. Las especies recolectadas fueron: Crataegus mexicana Moc \& Sessé ex DC. (tejocote), Pyrus communis L. (pera), Pyrus malus L. (manzana) subfamilia Maloideae, Prunus armeniaca L. (chabacano) y Prunus domestica L. (ciruela) subfamilia Prunoideae. La colecta se hizo en el estado de Puebla, en el municipio de San Felipe Teotlalcingo. Se muestreó un ejemplar por especie. Para el estudio macroscópico se usaron muestras de $15 \times 7 \times 1 \mathrm{~cm}$ y para el microscópico se hicieron laminillas fijas de cortes y de material disociado. Se obtuvieron tablillas y cortes de los tres planos de la madera que son el transversal, tangencial y radial. A los elementos mensurables se les hizo un análisis estadístico univariado y se clasificaron con base en la media. La madera de las cinco especies presentó características macroscópicas y microscópicas semejantes, aunque hubo diferencias entre las especies de la misma subfamilia y más notables entre las dos subfamilias. El propósito del estudio fue proponer el uso de su madera, ya que generalmente la madera de estos árboles frutales no se aprovecha cuando se derriban una vez que han dejado de ser productivos.

PALABRAS CLAVE:

Anatomía, frutales, madera, Puebla, Rosaceae.

\begin{abstract}
The macroscopic and microscopic anatomical description of the wood of five fruit species of the Rosaceae family is described. Species of Crataegus mexicana Moc \& Sessé ex DC. (Hawthorn), Pyrus communis L. (Pear), Pyrus malus L. (Apple) Maloideae subfamily, Prunus armeniaca L. (Peach) and Prunus domestica L. (Plum) Prunoideae subfamily were collected. The state of Puebla, Municipality of San Felipe Teotlalcingo was the collection site. One tree by species was recollected. The macroscopic study was made in wood samples of $15 \times 7 \times 1 \mathrm{~cm}$ and the microscopic study this was made by using slides of dissociated material and cuts from a cube. Samples of wood and slides showed the three typical planes of wood, namely, transverse cross section, tangential and radial. A univariate statistic analysis was performed to the quantitative elements, which were classified according to their average. The five wood species showed similar macroscopic and microscopic characteristics between subfamily, although there were differences between species of the same subfamily, these were stronger between both subfamilies. The purpose of the study was to suggest possible end uses for the wood of fruits trees, since generally speaking this is not used once the trees are no longer productive.
\end{abstract}

KEY WORDS:

Wood anatomy, fruits trees, Puebla, Rosaceae. 


\section{INTRODUCCIÓN}

La familia Rosaceae incluye desde hierbas y arbustos hasta árboles de tallas medianas y grandes. Se consideran unos 100 géneros y más de 2000 especies representadas en todo el mundo con la mayor diversidad en China (Zhang y Baas, 1992, Zhang et al., 1992, Calderón, 2001). Muchos géneros de la familia tienen importancia como frutales, ornamentales y como recurso maderable. En México con importancia frutal están los géneros Crataegus, Pyrus (Subfamilia Maloideae) y Prunus (Subfamilia Prunoideae).

En varias regiones del país existen plantaciones de frutales, lo que aumenta el valor de su madera, ya que al tener un manejo silvícola algunas propiedades de la madera se resaltan, como son el ancho de los anillos. Esta característica por sí sola aumenta el valor estético y tecnológico de la madera, principalmente las que presentan porosidad anular o semicircular (Kollman y Coté, 1978; Desch, 1991). Las plantaciones frutales en México son abundantes en climas templado y tropical. Sin embargo, la madera de la mayoría de las especies no se aprovecha al término de su ciclo frutal y en el mejor de los casos se utiliza como leña, desaprovechando este valioso recurso forestal maderable (Borja et al., 1997; Mendoza y de la Paz Pérez, 2005). El desconocimiento de las propiedades de la madera,así como la apertura de un mercado limita su utilización. Es necesario implementar un adecuado plan de manejo que incluya el interés por utilizarlas.

Para México se han publicado algunos trabajos donde se resaltan las características anatómicas de la madera de árboles con importancia como frutales. Huerta y Becerra (1976), hicieron un estudio sobre la características anatómicas y físicas de 17 maderas del estado de Campeche, donde incluyen a Manil kara zapota (chicozapote, Sapotaceae). Destacan su uso maderable en poca escala y la recomiendan con base en su anatomía, para artículos torneados y decoración de interiores. Si también se consideran las propiedades físicas, se pueden usar en pisos, chumaceras, lanzaderas, construcciones navales y partes de instrumentos musicales.

Barajas (1980) estudió la anatomía de la madera de 10 especies de un bosque templado caducifolio cercano a Xalapa, Veracruz. Incluye a Crataegus mexicana (tejocote, Rosaceae), Prunus serotina (capulín, Rosaceae), Persea americana (aguacate, Lauraceae) y Psidium guajava (guayaba, Myrtaceae), donde recalca la importancia de ampliar este tipo de estudios que den información biológica y ecológica que permitan fomentar plantaciones y hacer un uso racional de las especies. Guridi (1980), al tratar sobre las artesanías de madera del estado de Michoacán, incluye a Mangi fera indica (mango, Anacardiaceae) y a Persea americana (aguacate, Lauraceae). Sin embargo, para la primera menciona que únicamente se utilizan las ramas provenientes de podas, para elaborar medallones y para madera ensamblada. Sugiere que con base en sus características anatómicas se amplíe su uso para figuras talladas a mano. Para el aguacate, dada la gran producción en Uruapan, los artesanos utilizan la madera para fondos y costillas de guitarras comerciales, en fruta tallada y pintada y como sustituto de Alnus arguta (aile, Betulaceae) resaltando entre otras características que no se raja. El aile es una madera altamente apreciada por los artesanos en la elaboración de las típicas bateas negras y decoradas con hoja de oro.

De la Paz Pérez et al. (1982) en un estudio que realizaron de 26 angios- 
permas recolectadas en bosques de clima templado de varios estados de la República Mexicana, incluyen a Prunus brachybotrya (cerezo montés, Rosaceae) y $P$. rhamnoides (coralillo, Rosaceae) y con base en las características de la madera sugieren usos donde destaque su belleza. A P. brachybotrya la sugieren como sustituto de Cedrela odorata (cedro rojo, Meliaceae), principalmente por su veteado, textura e hilo. Rogel (1982) incluye a Persea americana (aguacate, Lauraceae) la cual se recolectó en un bosque mesófilo de montaña en el estado de Guerrero y la sugiere en usos donde se manifiesten sus excelentes características estéticas.

Borja et al. (1997) estudiaron algunas características tecnológicas de la madera del género Crataegus de San Miguel Tlaixpan, México, resaltando su valor como leña por su alto valor calorífico, liberación gradual de energía y por el poco humo que desprende. Además, mencionan algunos usos locales en artículos de labranza basados en su densidad.

Tenango et al. (2004) dan a conocer las características de seis especies recolectadas en un huerto familiar del estado de Morelos: Annona cherimola (chirimoya, Annonaceae), Citrus sinensis (naranjo, Rutaceae), Ficus carica (higuera, Moraceae), Prunus persica (durazno, Rosaceae), Prunus serotina spp. capuli (capulín, Rosaceae) y Psidium guajava (guayaba, Mirtaceae), destacando sus excelentes características anatómicas y con base en éstas, sugieren usos en artesanías, juguetes, artículos decorativos, artículos torneados y escultura.

Mendoza y de la Paz Pérez (2005), con base en la anatomía de la madera sugieren el uso de la madera de cinco especies de la familia Rosaceae provenientes de Puebla.

Es conveniente señalar que en países como EUA, Canadá, y algunos europeos y asiáticos, la madera de varias especies de Pyrus y Prunus tiene usos muy especiales por las características estéticas y microscópicas (Kribs, 1968; Rendle, 1969; Jane, 1970; Panshin y de Zeeuw, 1970).

\section{OBJETIVO}

Con el fin de contribuir a un aprovechamiento integral de los árboles frutales se plantea como objetivo conocer las propiedades anatómicas de la madera de cinco especies de la familia Rosaceae, recolectadas en una plantación del estado de Puebla que fueron Crataegus mexicana Moc \& Sessé ex DC. (tejocote), Pyrus communis L. (pera), Pyrus malus L. (manzana) subfamilia Maloideae, Prunus armeniaca L. (chabacano) y Prunus domestica L. (ciruela) subfamilia Prunoideae, para que una vez que haya concluido su ciclo frutal, su madera pueda ser aprovechada incorporándose al mercado nacional. 


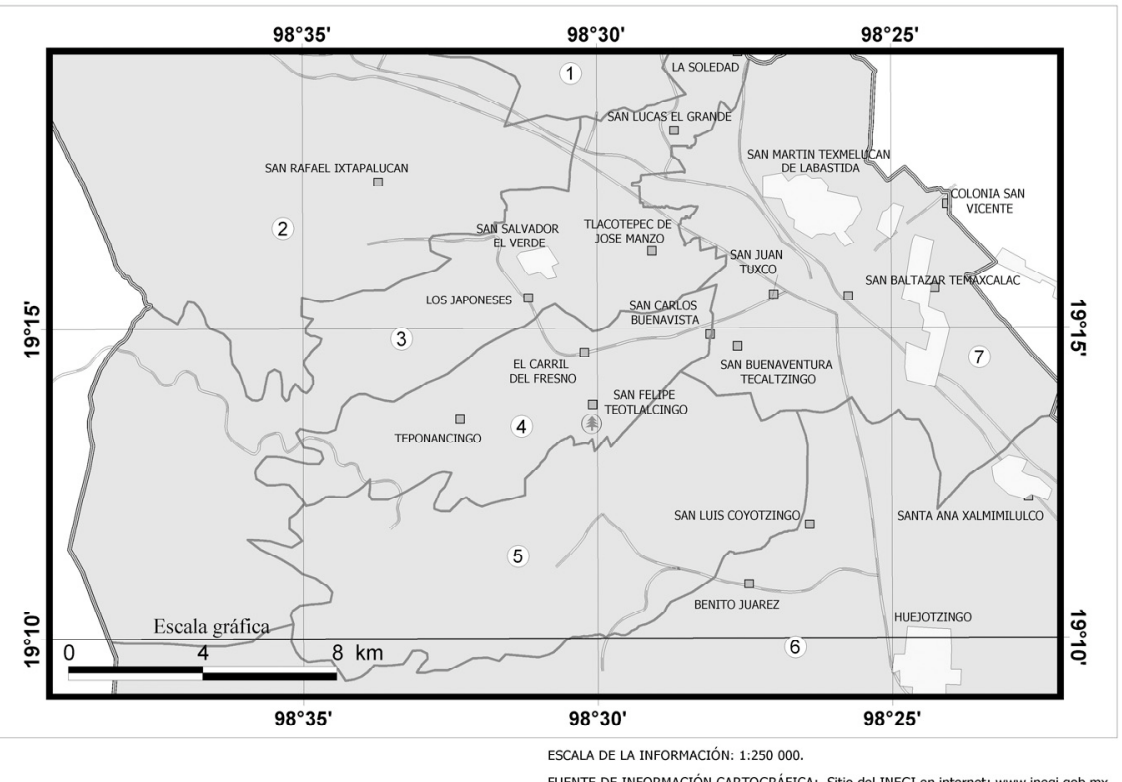

\section{Simbología}

(4) Ejido La Esperanza

Límite estatal

$\curvearrowright$ Límite municipal Municipio:

1. San Martín Tlalancaleca

2. Tlahuapan

3. San Salvador El Verde

4. San Felipe Teotlalcingo

5. Chiautzingo

6. Huejotzingo

7. San Martín Texmelucan

Carreteras principales

Áreas urbanas

Localidades vecinas

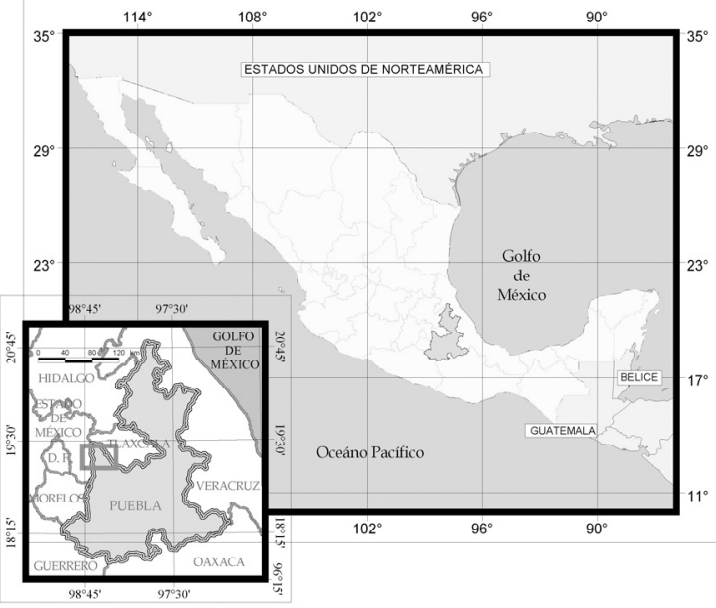

Figura 1. Ubicación del sitio de recolección. 


\section{MATERIAL Y MÉTODOS}

La madera de las especies se obtuvo de cinco árboles recolectados en una plantación de árboles frutales, en el municipio de San Felipe Teotlalcingo, Puebla (Fig. 1). Se cortaron cubos de $2 x$ $2 \mathrm{~cm}$, los que se ablandaron a ebullición en agua destilada entre 8 a 10 horas. De ellos se obtuvieron cortes de 15 a $20 \mu \mathrm{m}$ de grosor, en los planos transversal, tangencial y radial.

Los cortes se tiñeron con safraninaverde rápido durante dos minutos, se lavaron con agua destilada y se deshidrataron en alcoholes al 30\%, 50\%, $70 \%$, $96 \%$ y $100 \%$, realizándose dos cambios de cinco minutos en cada uno. Posteriormente se colocaron en xilol y finalmente se montaron con resina sintética.

De los cubos se cortaron pequeñas virutas, las cuales se colocaron en tubos de ensaye agregándoles solución de Jeffrey (Johansen, 1940). Posteriormente, el material se lavó con agua destilada, hasta eliminar la solución y se tiñó con pardo de Bismarck para hacer preparaciones fijas que se montaron con gelatina glicerinada.

A los elementos mensurables se les hizo un análisis univariado y se clasificaron con base en la media de acuerdo con Chattaway (1932) y IAWA Committee (1937, 1939). Las descripciones microscópicas se hicieron de acuerdo con IAWA Committee $(1964,1989)$. Para la descripción de los radios también se consideró lo que propone Kribs (1968).
Para describir las características macroscópicas se obtuvieron tablillas de $15 \times 7 \times 1 \mathrm{~cm}$ y se determinaron usando las tablas de clasificación de Tortorelli (1956) y para el color las tablas de Munsell Color (1990). Para cada especie se describió: el color, el olor, el sabor, el brillo, el veteado, la textura, el hilo y la visibilidad de los anillos de crecimiento. De acuerdo con el estudio realizado se sugieren usos para la madera.

Los nombres comunes y las características botánicas se dieron según Bailey (1949), Font Quer (1982), Moreno (1984), Martínez (1989), Martínez (1994) y García (2002). Las muestras de madera se registraron en la Xiloteca UAMIZ y los ejemplares de respaldo se depositaron en el Herbario Metropolitano UAMIZ Dr. Ramón Riba y Nava (Tabla 6).

\section{Sitio de recolección}

El municipio de San Felipe Teotlalcingo, Puebla, se localiza entre las coordenadas $19^{\circ} 14^{\prime}$ de latitud Norte y $98^{\circ} 30^{\prime}$ de longitud Oeste, en la Provincia Fisiográfica Eje Neovalcánico, Subprovincia Sierras Orientales. El clima es templado subhúmedo con abundantes lluvias en verano $(\mathrm{Cw})$, la temperatura media anual es de $22^{\circ} \mathrm{C}$, la precipitación media es de $1500 \mathrm{~mm}$ y su altitud promedio es de 2420 msnm (INEGI, 2002). 


\section{RESULTADOS}

\section{Descripción de las especies}

\section{Crataegus mexicana Moc \& Sessé ex DC. (Lám. 1)}

Subfamilia: Maloideae

Nombre común: Tejocote

\section{Características botánicas (Lám. 1. a-e)}

Árbol monoico caducifolio de $8 \mathrm{~m}$ de altura, corteza lisa gris claro, hojas simples, alternas, de forma romboideelípticas o lanceoladas, borde aserrado, ápice agudo y base cuneada, pubescentes. Flores en corimbos terminales de cinco pétalos, blancas o amarillas. Fruto en pomo, redondo, de color naranja.

\section{Características macroscópicas (Lám 1. f-g)}

La madera no presenta diferencia de color entre albura y duramen, es amarillo rojizo (5YR 7/6), sin olor ni sabor característicos, el brillo es bajo, el veteado es liso, la textura es fina y el hilo es recto.
Los anillos de crecimiento están marcados por una hilera de vasos en la madera temprana y por una a tres hileras de fibras en la madera tardía.

\section{Características microscópicas (Tabla 1 y Lám. 1. h-j)}

La madera presenta porosidad difusa, la mayoría de los poros son solitarios y pocos son múltiples radiales de 2 , son muy numerosos, de contorno oval, de diámetro tangencial pequeño. Los elementos de vaso son medianos, sus paredes presentan punteaduras areoladas alternas, redondas a ovales, la platina de perforación es simple y la pared terminal es oblicua. Algunos presentan gomas. El parénquima axial es apotraqueal difuso agregado. Los radios son pocos, uniseriados, de 8 células de altura y la mayoría son biseriados, numerosos, heterogéneos, muy bajos y finos. Las punteaduras de radio-vaso son semejantes a las intervasculares. Ambos parénquimas presentan gomas y el radial presenta cristales prismáticos. Las fibras son de tipo fibrotraqueida, de longitud corta, de diámetro fino y de pared delgada. 


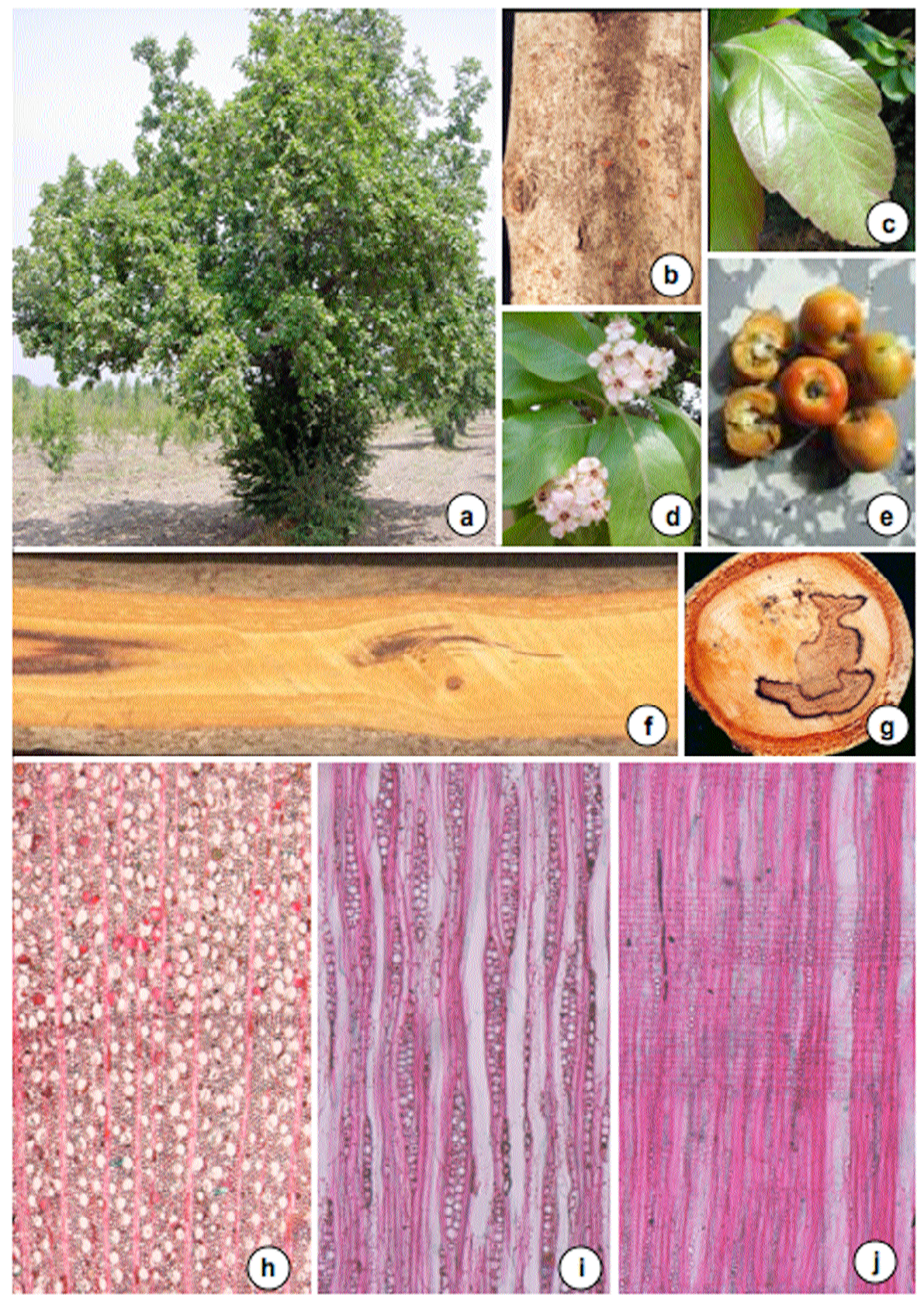

Lámina 1. Crataegus mexicana Moc \& Sessé ex DC. (tejocote). a. árbol. b. corteza. c. hojas. d. flor. e. fruto. f. tablilla tangencial. g. rodaja. h. corte transversal (5x). i. corte tangencial (10x). j. corte radial (10x). 

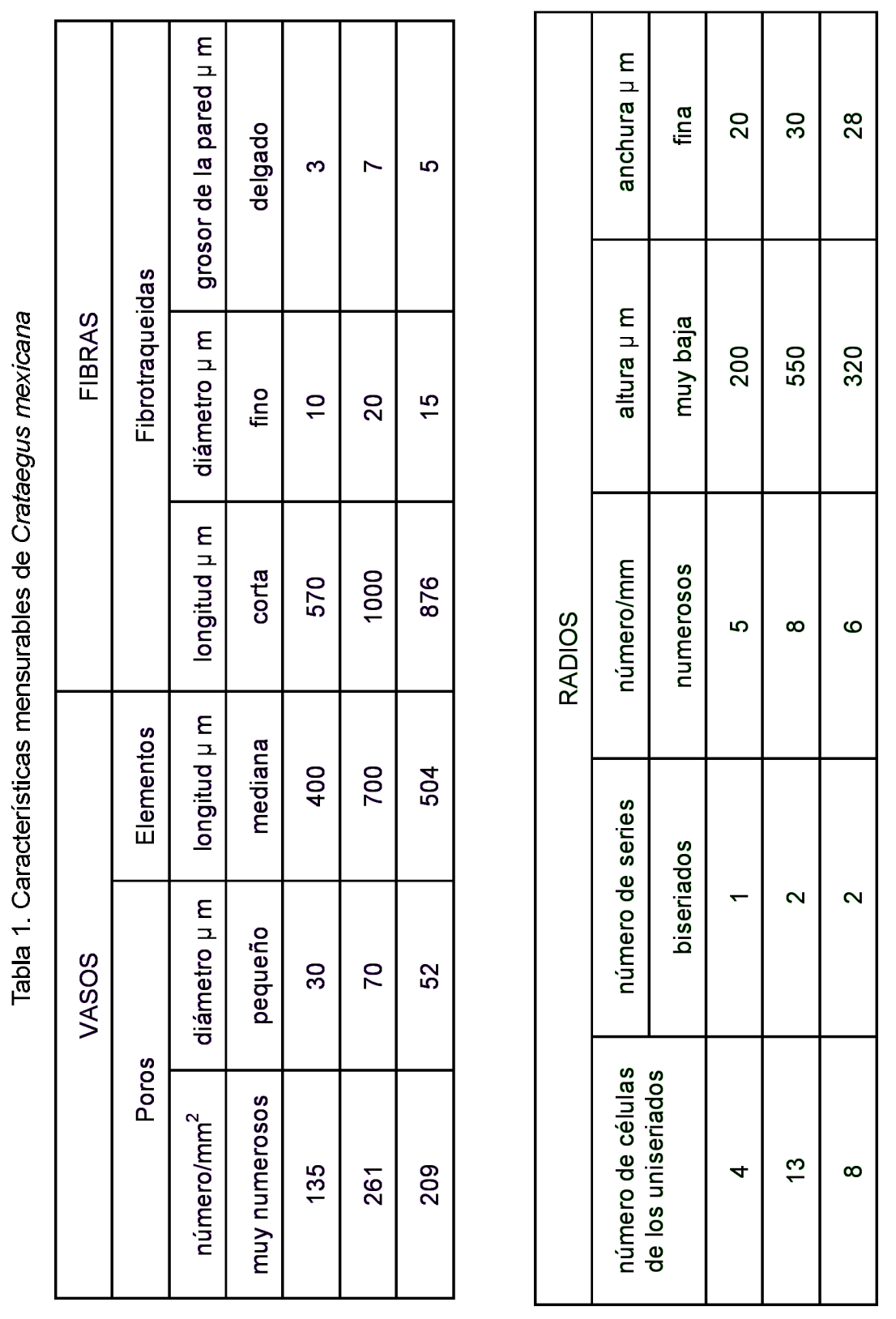


\section{Pyrus communis L. (Lám. 2)}

Subfamilia: Maloideae

Nombre común: Pera

Características botánicas (Lám. 2. a-e)

Árbol monoico caducifolio de $8 \mathrm{~m}$ de altura, corteza escamosa castaño grisáceo, hojas simples, alternas, de forma oval, borde finamente aserrado, ápice agudo, base obtusa, glabras. Flores solitarias con cuatro a cinco pétalos de color blanco, con numerosos estambres. Fruto en pomo, ovado, de color verde.

\section{Características macroscópicas (Lám 2. f-g)}

La madera no presenta diferencia de color entre albura y duramen, es amarillo rojizo (7.5YR 7/6), sin olor ni sabor característicos, el brillo es bajo, el veteado es liso, la textura es fina y el hilo es recto. Los anillos de crecimiento están marcados por una hilera de vasos en la madera temprana y por una a dos hileras de fibras en la madera tardía.

\section{Características microscópicas (Tabla 2 y Lám. 2. h-j)}

La madera presenta porosidad difusa, la mayoría de los poros son solitarios y pocos son múltiples radiales de 2 y 3 , son muy numerosos, de contorno oval, de diámetro tangencial muy pequeño. Los elementos de vaso son medianos, sus paredes presentan punteaduras areoladas alternas, redondas a ovales, la platina de perforación es simple y la pared terminal es oblicua. Algunos presentan gomas. El parénquima axial es apotraqueal difuso agregado. Los radios son pocos, uniseriados, de 8 células de altura y la mayoría son biseriados, numerosos, homogéneos, muy bajos y finos. Ambos parénquimas presentan gomas. Las punteaduras de radio-vaso son semejantes a las intervasculares. Las fibras son de tipo fibrotraqueida, de longitud corta, de diámetro fino y de pared delgada. 

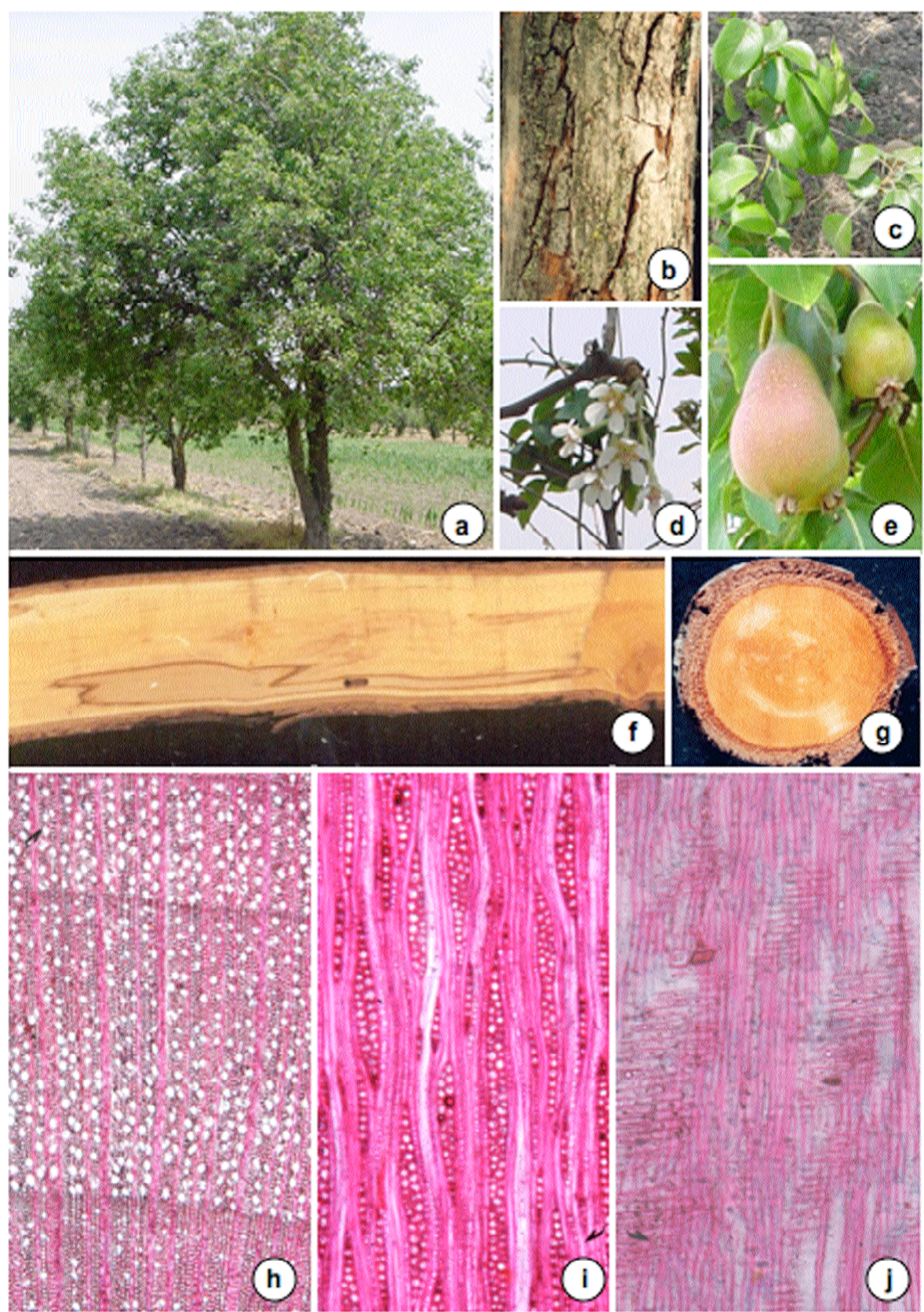

Lámina 2. Pyrus communis L. (pera). a. árbol. b. corteza. c. hojas. d. flor. e. fruto. f. tablilla tangencial. g. rodaja. h. corte transversal (5x). i. corte tangencial (10x). j. corte radial $(10 x)$. 

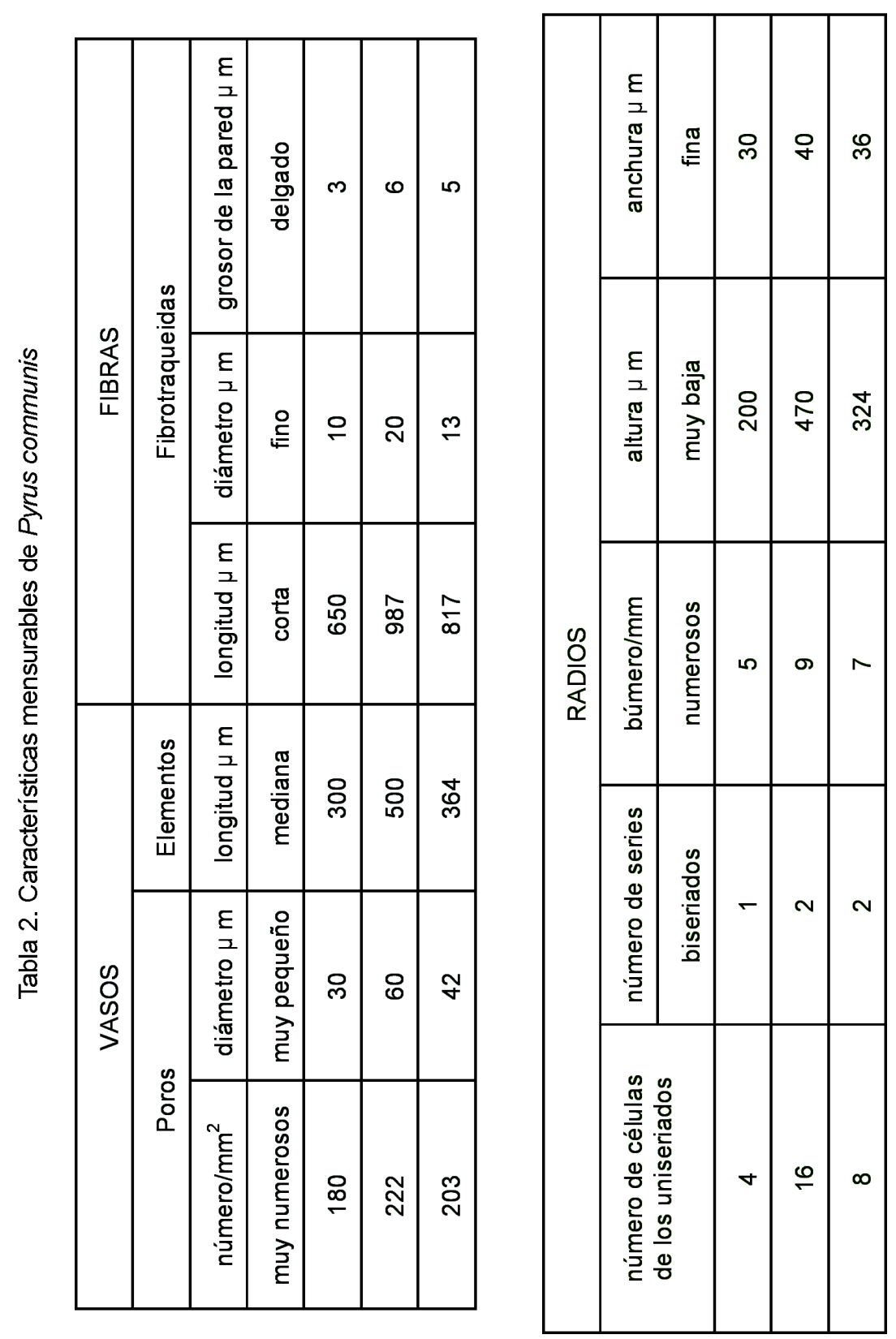


\section{Pyrus malus L. (Lám. 3)}

Subfamilia: Maloideae

Nombre común: Manzana

\section{Características botánicas (Lám. 3. a-e)}

Árbol monoico caducifolio de $6 \mathrm{~m}$ de altura, corteza lisa castaño grisáceo, hojas simples, alternas, de forma oval, borde aserrado, ápice agudo, base asimétrica, pubescente principalmente en las venas. Flores solitarias con cuatro a cinco pétalos de color rosa, con numerosos estambres. Fruto en pomo, redondo, de color rojo.

\section{Características macroscópicas} (Lám. 3. f-g)

La madera no presenta diferencia de color entre albura y duramen, es castaño muy pálido (10YR 8/4), sin olor ni sabor característicos, el brillo es bajo, el veteado es liso, la textura es fina y el hilo es recto. Los anillos de crecimiento están marcados por varias hileras de vasos en la madera temprana y por una a dos hileras de fibras en la madera tardía.

\section{Características microscópicas (Tabla 3 y Lám. 3. h-j)}

La madera presenta porosidad difusa, los poros de la madera temprana forman de 3 a 4 hileras al principio del anillo, la mayoría de los poros son solitarios y pocos son múltiples radiales de 2 , son muy numerosos, de contorno oval, de diámetro tangencial pequeño. Los elementos de vaso son medianos, sus paredes presentan punteaduras areoladas alternas, redondas a ovales, la platina de perforación es simple y la pared terminal es oblicua. Algunos presentan gomas. El parénquima axial es apotraqueal difuso agregado. Los radios son pocos uniseriados, de 9 células de altura y la mayoría son biseriados, numerosos, homogéneos, muy bajos y finos. Las punteaduras de radio-vaso son semejantes a las intervasculares. Ambos parénquimas presentan gomas. Las fibras son de tipo fibrotraqueida, de longitud mediana, de diámetro fino y de pared delgada. 


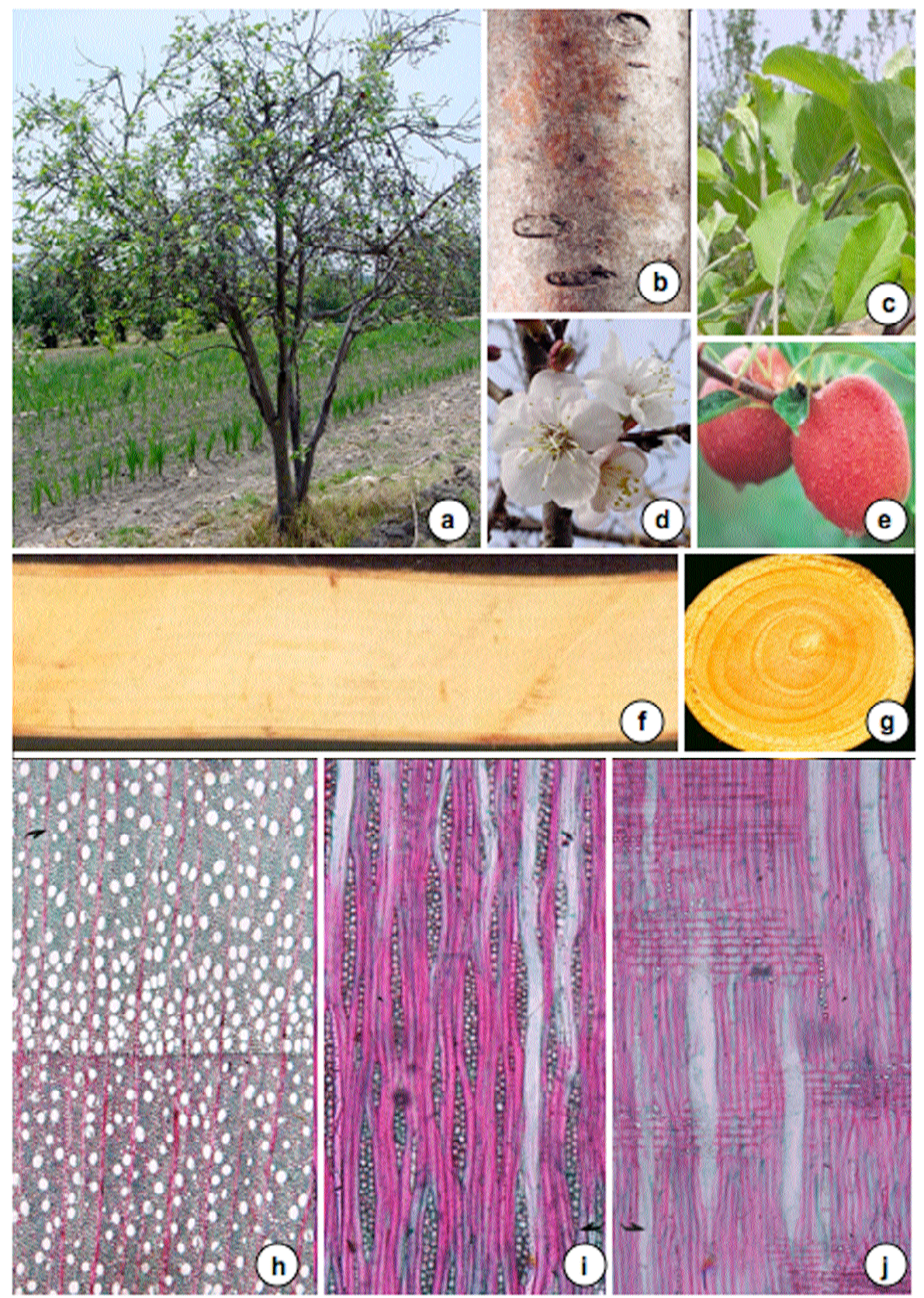

Lámina 3. Pyrus malus L. (manzana). a. árbol. b. corteza. c. hojas. d. flor. e. fruto. f. tablilla tangencial. g. rodaja. h. corte transversal $(5 x)$. i. corte tangencial $(10 x)$. j. corte radial $(10 x)$. 

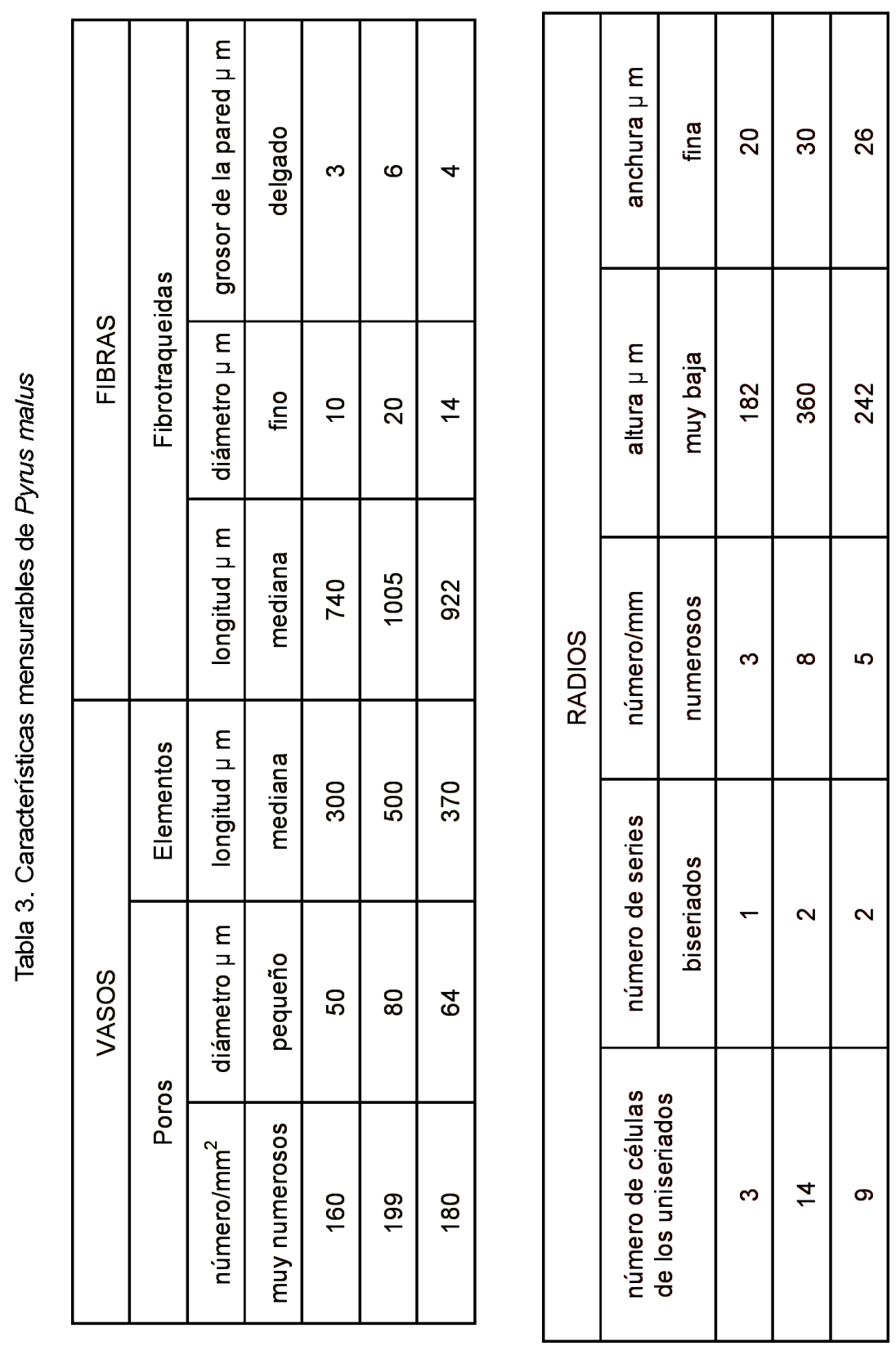


\section{Prunus armeniaca L. (Lám. 4)}

Subfamilia: Prunoideae

Nombre común: Chabacano

Características botánicas (Lám. 4. a-e)

Árbol monoico caducifolio de $8 \mathrm{~m}$ de altura, corteza escamosa castaño grisáceo, hojas simples, alternas, de forma cordiforme, borde aserrado, ápice acuminado, base auriculada, envés pubescente en las nervaduras. Flores en racimos, rosas o blancas. Fruto en drupa, redondo, de color amarillo naranja.

\section{Características macroscópicas (Lám 4. f-g)}

La madera presenta diferencia de color entre albura y duramen, la albura es rojizo amarillento (7.5YR 8/6) y el duramen castaño (7.5YR $5 / 3$ ), sin olor ni sabor característicos, el brillo es mediano, el veteado es liso, la textura es fina y el hilo es recto. Los anillos de crecimiento están marcados por la diferencia en el diámetro de los vasos de la madera temprana y los de la madera tardía.

\section{Características microscópicas (Tabla 4 y Lám. 4. h-j)}

La madera presenta porosidad anular, los poros de la madera temprana forman una hilera al principio del anillo, la mayoría de los poros son solitarios y pocos son múltiples radiales de 2 a 4 , son de numerosos a muy numerosos, de contorno oval, de diámetro tangencial mediano y muy pequeño. Los elementos de vaso son de cortos a medianos, sus paredes presentan punteaduras areoladas alternas, poligonales y engrosamientos en espiral, la platina de perforación es simple y la pared terminal es oblicua. Presentan abundantes gomas. El parénquima axial es apotraqueal difuso y escaso paratraqueal vasicéntrico. Los radios son pocos uniseriados, de 9 células de altura y la mayoría son tetraseriados, numerosos, heterogéneos III, muy bajos y medianos. Las punteaduras de radio-vaso son semejantes a las intervasculares. Ambos parénquimas presentan gomas. Las fibras son de tipo fibrotraqueida, de longitud corta, de diámetro fino y de pared delgada. 

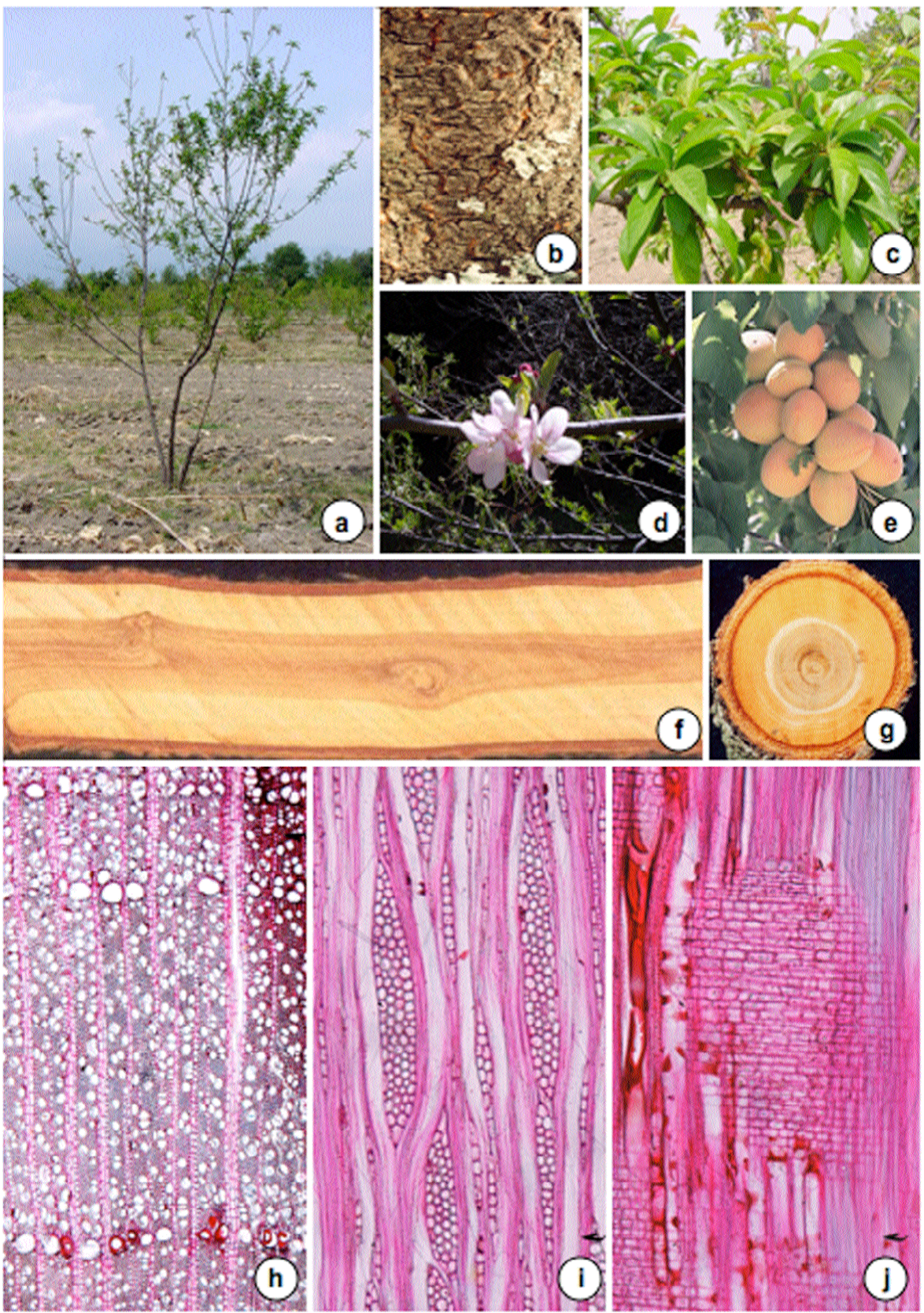

Lámina 4. Prunus armeniaca L. (chabacano). a. árbol. b. corteza. c. hojas. d. flor. e. fruto. f. tablilla tangencial. g. rodaja. h. corte transversal (5x). i. corte tangencial (10x). j. corte radial $(10 x)$. 


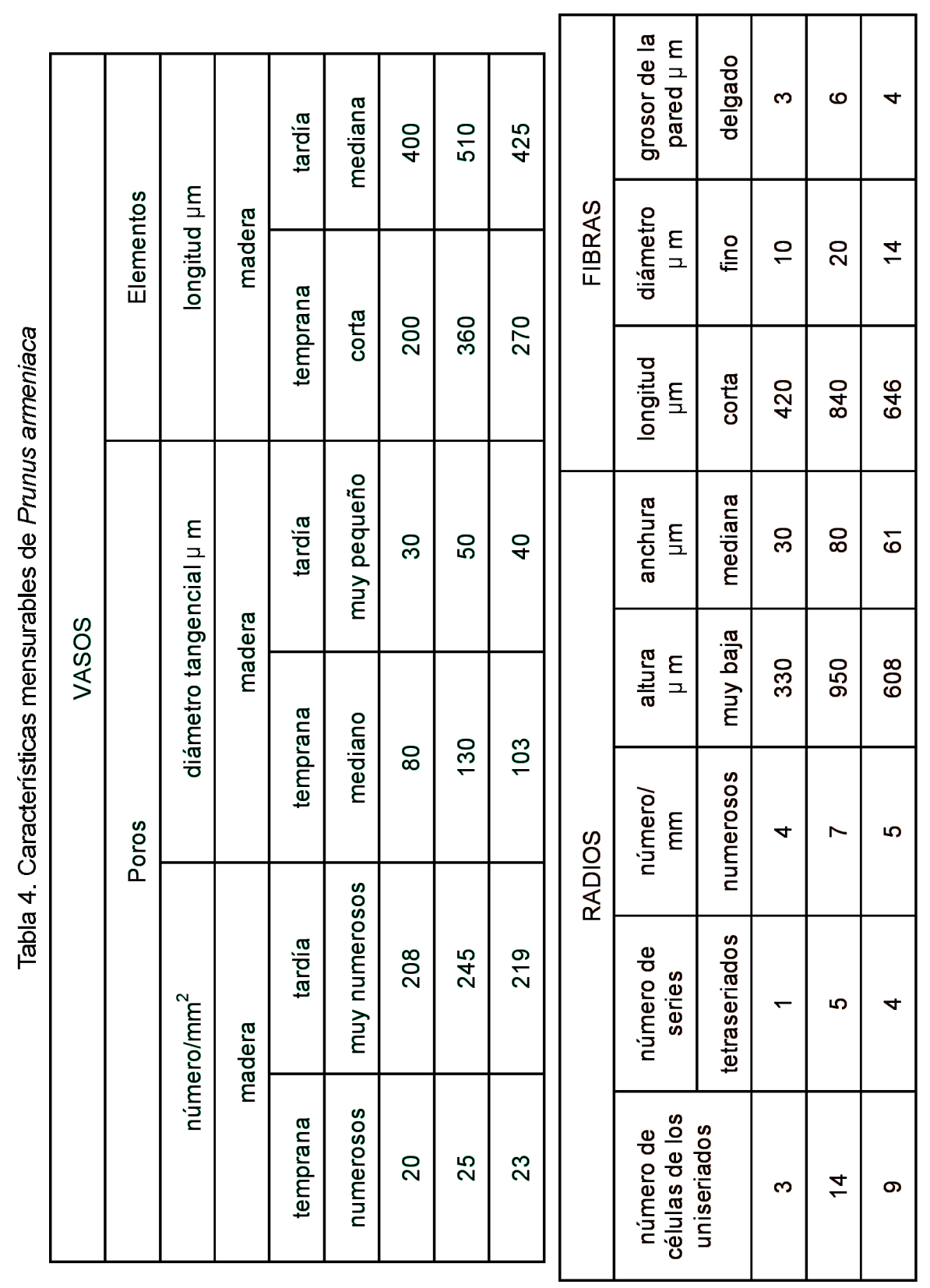




\section{Prunus domestica L. (Lám. 5)}

Subfamilia: Prunoideae

Nombre común: Ciruela

\section{Características botánicas (Lám. 5. a-e)}

Árbol monoico caducifolio de $8 \mathrm{~m}$ de altura, corteza fisurada gris rojizo, hojas simples, alternas, de forma ovada a elíptica borde aserrado, ápice acuminado, base cuneada, con el envés púrpura. Flor con cuatro o cinco pétalos de color rosa pálido, con numerosos estambres y olor agradable. Fruto en drupa, redondo de color púrpura.

\section{Características macroscópicas} (Lám 5. f-g)

La madera presenta diferencia de color entre albura y duramen, la albura es amarillo rojizo (7.5YR 8/4) y el duramen rojo claro (10R 5/4), sin olor ni sabor característicos, el brillo es bajo, el veteado es liso, la textura es fina y el hilo es recto. Los anillos de crecimiento están marcados por varias hileras de vasos en la madera temprana y por una a dos hileras de fibras en la madera tardía.

\section{Características microscópicas (Tabla 5 y Lám. 5. h-j)}

La madera presenta porosidad semicircular, los poros de la madera temprana forman varias hileras al principio del anillo, la mayoría de los poros son solitarios, pocos son múltiples radiales de 2 a 3 y agrupados, son muy numerosos, de contorno oval, de diámetro tangencial pequeño. Los elementos de vaso son cortos, sus paredes presentan punteaduras areoladas alternas poligonales y engrosamientos en espiral, la platina de perforación es simple y la pared terminal es oblicua. Algunos presentan gomas. El parénquima axial es apotraqueal difuso. Los radios son pocos uniseriados, de 6 células de altura y la mayoría son pentaseriados, numerosos, heterogéneos III, muy bajos y medianos. Ambos parénquimas presentan gomas. Las punteaduras de radio-vaso son semejantes a las intervasculares. Las fibras son de tipo fibrotraqueida, de longitud corta, de diámetro fino y de pared delgada. 


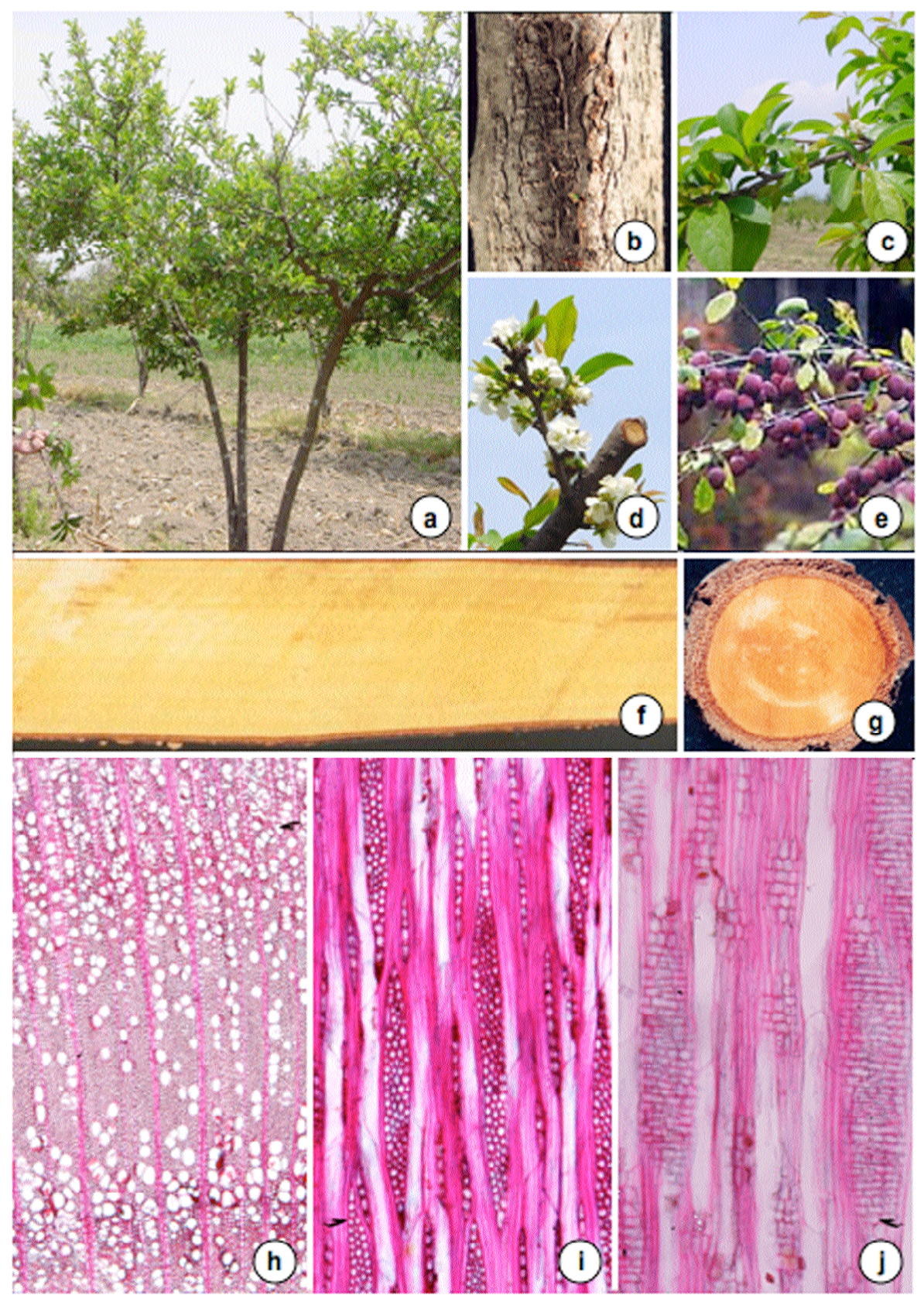

Lámina 5. Prunus domestica L. (ciruela). a. árbol. b. corteza. c. hojas. d. flor. e. fruto. f. tablilla tangencial. g. rodaja. h. corte transversal $(5 x)$. i. corte tangencial $(10 x)$. j. corte radial $(10 x)$. 


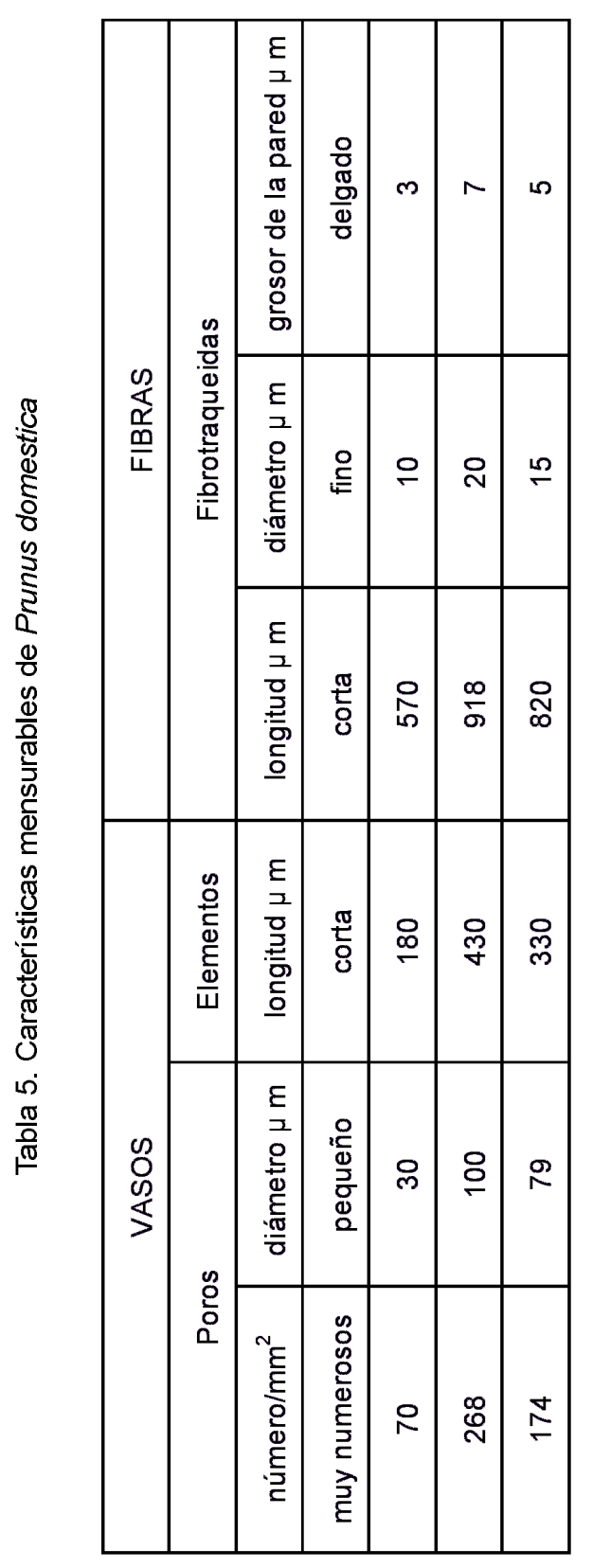

\begin{tabular}{|c|c|c|c|c|c|}
\hline \multirow{3}{*}{ 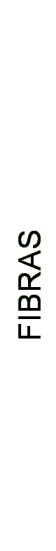 } & 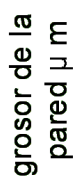 & $\begin{array}{l}\frac{0}{0} \\
\frac{\pi}{0} \\
\frac{0}{0} \\
\frac{1}{0}\end{array}$ & $m$ & 0 & $\nabla$ \\
\hline & 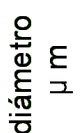 & $\stackrel{ }{\rightleftarrows}$ & 으 & ని & $\stackrel{\nabla}{ }$ \\
\hline & $\begin{array}{l}\text { 올 } \\
\text { 틀 } \\
\text { 으 }\end{array}$ & $\begin{array}{l}\frac{\pi}{2} \\
\text { Lे }\end{array}$ & 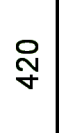 & $\underset{\infty}{\stackrel{P}{\square}}$ & \& \\
\hline \multirow{5}{*}{ 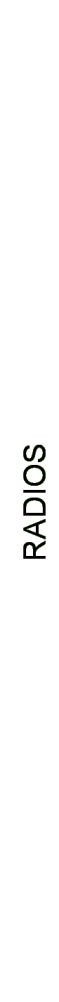 } & 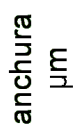 & 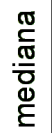 & ర্লি & ০ & $\bar{\sigma}$ \\
\hline & $\begin{array}{l}\frac{\pi}{\underline{\underline{I}}} \\
\frac{\varepsilon}{\pi} \\
=\end{array}$ & 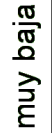 & 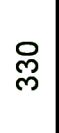 & 吕 & $\stackrel{\infty}{\circ}$ \\
\hline & 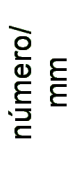 & 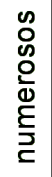 & $\nabla$ & $r$ & ما \\
\hline & 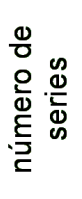 & 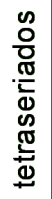 & - & ما & $\nabla$ \\
\hline & \multicolumn{2}{|c|}{ 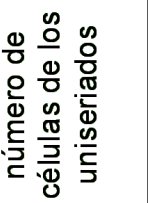 } & m & $\stackrel{\nabla}{\forall}$ & $\sigma$ \\
\hline
\end{tabular}




\section{DISCUSIÓN Y CONCLUSIONES}

Las características macroscópicas y microscópicas son semejantes en la madera de las cinco especies en los tonos claros, olor y sabor no característicos, veteado liso, textura fina, hilo recto, anillos de crecimiento marcados, abundancia y forma de los poros, tipo de las punteaduras intervasculares, platina perforada y paredes terminales de los elementos vasculares, distribución y tipo de parénquima axial, tipo, abundancia y altura de los radios y características de las fibras.

Los tonos de la madera se presentaron de amarillo a naranja. Las dos especies de Prunus mostraron diferencia entre albura y duramen, los anillos de crecimiento están marcados por fibras o por vasos o por ambos elementos, los poros son numerosos de contorno oval, los elementos de vaso con punteaduras areoladas alternas con platina de perforación simple y paredes terminales oblicuas, parénquima difuso en agregados, radios uniseriados y multiseriados, numerosos y bajos y fibras de tipo fibrotraqueida, de longitud corta, de diámetro fino y pared delgada (Lám. 1 al $5 \mathrm{f}-\mathrm{j}$ y tablas 1 al 5).

También se observaron diferencias en la madera entre las especies en el tipo de porosidad, en la forma de las punteaduras y presencia o ausencia de engrosamientos en espiral en los elementos vasculares, clase, composición celular, anchura y número de series de los radios y en la abundancia y tipo de los contenidos celulares.

Las tres especies de la subfamilia Maloideae: Crataegus mexicana (tejocote), Pyrus communis (pera) y Pyrus malus (manzana), presentaron porosidad difusa y de las dos especies de la subfamilia Prunoideae: Prunus armeniaca (chabacano) presentó porosidad anular y Prunus domestica (ciruela) presentó porosidad semicircular. Las punteaduras intervasculares en las especies de la subfamilias Maloideae son redondas a ovales y en las especies de la subfamilia Prunoideae son poligonales y los elementos de vaso presentan engrosamientos en espiral (Lám. 1 al 5 h y Lám. 6 b, c y e).

Con relación a los radios, en Pyrus communis (pera) y Pyrus malus (manzana) son homogéneos formados de células procumbentes, en la última especie están formados de células procumbentes de diferente tamaño, biseriados, bajos y finos. En Crataegus mexi cana (tejocote) (Maloideae) son heterogéneos, el cuerpo formado de células procumbentes y en los márgenes con una hilera de células cuadradas, biseriados, bajos y finos, En las especies de Prunus (Prunoideae) son heterogéneos, de cuatro a cinco series y de anchura mediana. En Prunus armeniaca (chabacano) y Prunus domestica (ciruela), presentan el cuerpo de células procumbentes y varias hileras de células cuadradas en los márgenes. Las células parenquimatosas son de mayor tamaño en los radios de la subfamilia Prunoideae que en los de la familia Maloideae. Las punteaduras radio-vaso son similares a las intervasculares dependiendo de la subfamilia. En cuanto a los contenidos, las cinco especies presentaron gomas en los elementos vasculares y en ambos parénquimas, éstas son más abundantes en Prunus. Sólo Crataegus mexicana (tejocote), presentó escasos cristales prismáticos en el parénquima axial (Lám. 1 al $5 \mathrm{i}$-j, Lám. 6 a y d y tablas 1 al 5).

De acuerdo con los valores de las elementos anatómicos que presenta la madera de las especies estudiadas como son la altura baja y anchura fina o mediana no mayor de 80 micras de sus 


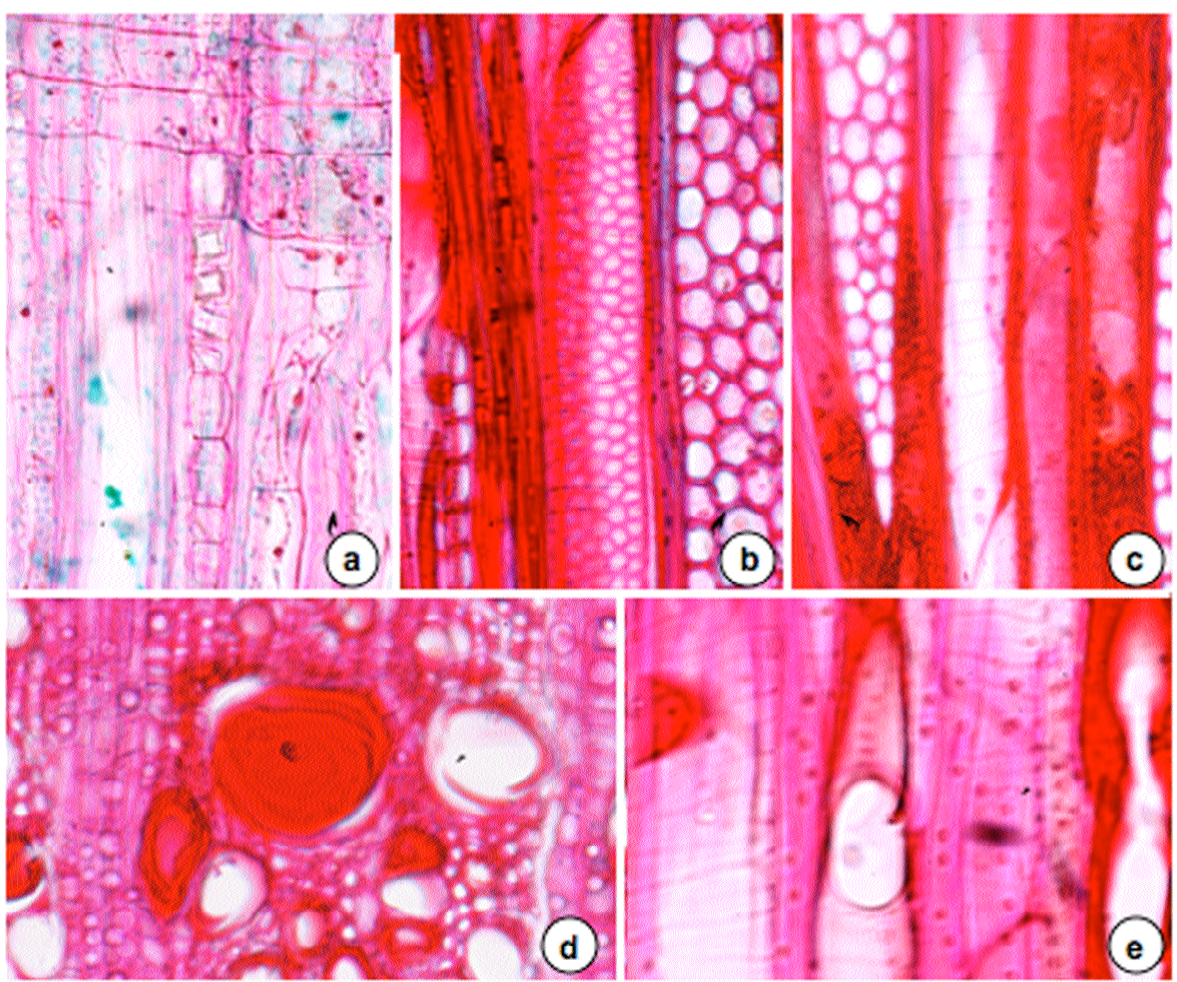

Lámina 6. Caracteres distintivos. a. Cristales prismáticos en el parénquima axial de Crataegus mexicana (tejocote). b. Punteaduras en un elemento de vaso de Prunus domestica (ciruela). c. Engrosamientos en espiral en un elemento de vaso de Prunus domestica (ciruela). d. Gomas en un poro de Prunus armeniaca (chabacano). e. Platina de perforación simple y engrosamientos en espiral en elementos de vaso de Prunus armeniaca (chabacano). Todas a 40x.

Tabla 6. Registro de las especies estudiadas

\begin{tabular}{|l|c|c|c|}
\hline \multirow{2}{*}{ Nombre científico } & \multirow{2}{*}{ Nombre común } & \multicolumn{2}{|c|}{ Registro } \\
\cline { 3 - 4 } & & Xiloteca & Herbario \\
\hline Crataegus mexicana & Tejocote & M-209 & 60794 \\
\hline Pyrus communis & Pera & M-212 & 60791 \\
\hline Pyrus malus & Manzana & M-213 & 60792 \\
\hline Prunus armeniaca & Chabacan o & M-210 & 60793 \\
\hline Prunus domestica & Ciruela & M-211 & 60795 \\
\hline
\end{tabular}


radios de una a cinco series, la longitud corta de sus fibras con paredes delgadas y diámetro fino, características que por sí solas tienen influencia en las propiedades tecnológicas como densidad, dureza, contracciones, favoreciendo su aserrío y secado, unidas a las características de su veteado liso a suave, textura fina a mediana, hilo recto que las hace fácil al maquinado como el torneado, lijado, clavado, pegado, etc., dando un terminado suave y un pulido uniforme, además de que estas características se ven favorecidas por las prácticas silvícolas ya que provienen de plantaciones con cuidados especiales con menos variación en los caracteres que son altamente influenciados por el medio, como son la anchura de los anillos de crecimiento, la porosidad, las dimensiones de los radios, los contenidos, entre otros (Kollman y Coté Jr., 1968; Jane, 1970; Panshin y de Zeeuw, 1970; Dinwoodie, 1985; De la Paz Pérez, 1985; Desch, 1991; De la Paz Pérez y Dávalos, 1995; De la Paz Pérez y Quintanar, 1997) por lo que se recomienda en la elaboración de productos de alta calidad e ir integrando este valioso recurso forestal a la economía nacional una vez que ha concluido su ciclo de producción frutal.

\section{USOS SUGERIDOS}

De acuerdo con las características anatómicas que presenta la madera de las especies estudiadas, como son colores claros, sin olor ni sabor característicos, veteado liso a suave, textura fina a mediana, hilo recto, anillos de crecimiento marcados, radios bajos $y$ angostos y fibras cortas de paredes delgadas, se recomienda para diversas artesanías, juguetes, muebles infantiles, marcos para cuadros, cajas, madera labrada, escultura, utensilios de cocina y donde se pongan de manifiesto sus excelentes características anatómicas.

\section{AGRADECIMIENTOS}

Las autoras agradecen al señor Zenón Toribio Gamboa dueño de la plantación, las facilidades brindadas para la recolección del material de estudio, a la bióloga Nery Alicia Tapia y a la M. en C. Irma Reyes la revisión del manuscrito, al señor Jorge Lodigiani su ayuda en el procesado del material fotográfico y al biólogo Miguel Bravo la elaboración de la figura 1.

\section{REFERENCIAS}

Bailey, H. L. 1949. Revised manual of cultivated plants. MacMillan, Nueva York, EUA. 1116 p.

Barajas, J. 1980. Anatomía de maderas de México No. 3. Diez especies del bosque caducifolio de las cercanías de Xalapa, Ver. México. Biotica 5(1):23-40.

Borja, A., D. Granados y J. Guzmán. 1997. Importancia comercial del tejocote. II Congreso Internacional de Etnobotánica. Mérida Yucatán. p 276

Calderón, G. 2001. Rosaceae. In: Calderón y Rzedowski. Flora Fanerogámica del Valle de México. Comisión Nacional de la BiodiversidadInstituto de Ecología, A.C., México. pp. 233-250.

Chattaway, M. M. 1932. Proposed standards for numerical values used in describing wood. Tropical Woods 29:20-28.

De la Paz Pérez O., C., P. Olvera C. y G. Corral L. 1982. Estudio anatómico de la madera de 26 especies de angiospermas de clima templado. Bol. Téc. Inst. Nac. Invest. For. México, No. 91. 122 p. 
De la Paz Pérez O., C. 1985.Variación en la estructura anatómica de los encinos y su efecto en el aprovechamiento de los mismos. II Seminario Nacional Sobre Utilización de Encinos. Pub. Esp. Inst. Nac. Invest. For. No. 49:291-312. México.

De la Paz Pérez O., C. y R. Dávalos S. 1995. Relación estructura propiedades de la madera de dos especies de Quercus. III Seminario Nacional Sobre Utilización de Encinos. Universidad Autónoma de Nuevo León. II:427.441.

De la Paz Pérez O., C. y A. Quintanar I. 1997. Las características tecnológicas de la madera. ContactoS. 19:15-21.

Desch, H. E. 1991. Timber, its structure and properties. Macmillan. $424 \mathrm{p}$.

Dinwoodie, J. H. 1985. Timber, a review of the structure, mechanical properties relationship. I. 104(1):3-32.

Font Quer, P. 1982. Diccionario de botánica. Labor. México, D. F. 1233p.

García, A. 2002. Los árboles de la Universidad Autónoma Metropolitana Iztapalapa. Servicio Social. Universidad Autónoma Metropolitana Iztapalapa. $135 \mathrm{p}$.

Guridi G., L. I. 1980. La madera en las artesanías del estado de Michoacán. Bol. Div. Inst. Nac. Invest. For. México, No. 50. 132p.

Huerta, J. y J. Becerra. 1976. Anatomía macroscópica y algunas características físicas de diecisiete maderas tropicales mexicanas. Bol. Div. Inst. Nac. Invest. For. México, No. 46. 61 p.

INEGI. 2000. Marco geoestadístico municipal. Formato Digital. México. www.inegi.gob.mx
INEGI. 2002. Anuario estadístico del estado de Puebla. Tomo 1. Secretaria de Programación y Presupuesto. 250 p.

IAWA Committee. 1937. Standars terms of length of vessels members and wood fibers. Tropical Woods 51:2122.

IAWA Committee. 1939. Standars terms of size for vessels diameter and ray width. Tropical Woods 59:51-52.

IAWA Committee. 1964. Multilingual glossary of terms used in wood anatomy. Verlagsanstalt, Suiza. $186 \mathrm{p}$.

IAWA Committee. 1989. IAWA list of microscopic features for hardwood identification. IAWA 10(3):219-332.

Jane, F. W. 1970. The structure of wood. Adam \& Charles Black. Londres. 478 p.

Johansen, D. A. 1940. Plant microtechnique. McGraw-Hill. Nueva York. 523 p.

Kollman, F. P.y W. A. Coté, Jr. 1968. Principles of wood science and technology I. Solid Wood. Springer-Verlag. Nueva York. 560 p.

Kribs, D. A. 1968. Commercial foreign woods on the american market. Dover Pub. Inc. Nueva York. 241 p.

Martínez, L. 1989. Estudio descriptivo de los árboles más comunes de la Ciudad de México. Tesis. Facultad de Ciencias. Universidad Nacional Autónoma de México. México. 268 p.

Martínez, M. 1994. Catálogo de nombres vulgares y científicos de plantas mexicanas. Fondo de Cultura Económica. $1247 \mathrm{p}$.

Mendoza A., M. y C. de la Paz Pérez O. 2005. La madera de algunas espe- 
cies frutales de la familia Rosaceae. XXIX Congreso Mexicano de Histología. Tlaxcala, Tlax. p. 74

Moreno, N. P. 1984. Glosario botánico ilustrado. Instituto Nacional de Investigaciones Sobre Recursos Bióticos. Xalapa, Veracruz, México. 300 p.

Munsell Color. 1990. Munsell soil color charts. Baltimore, Maryland. $17 \mathrm{p}$.

Panshin, A. J. y C. de Zeeuw. 1970. Textbook of wood technology. I. McGrawHill. Nueva York. 705 p.

Rendle, B. J. 1969. World timbers. 1. Europe \& Africa. Ernest Benn Limited-University of Toronto Press. $191 \mathrm{p}$.

Rogel, M. de los A. 1982. Estudio anatómico de la madera de seis especies tropicales. Bol. Téc. Inst. Nac. Invest. For. México, No. 89. 70 p.
Tenango C., M., De la Paz Pérez, O., C. y J. Rivera T. 2004. Anatomía de la madera de seis especies de árboles frutales. V Congreso Mexicano de Tecnología de Productos Forestales. Pachuca, Hgo. Mesa 6.

Tortorelli, L. 1956. Maderas y bosques argentinos. ACME. Buenos Aires. 910 p.

Zhang, S. Y. y P. Baas. 1992. Wood anatomy of tress and shubs from China. III. Rosaceae. IAWA Bull. new series 13(1):21-92.

Zhang, S. Y., P. Baas y M. Zandee. 1992. Wood structure of the Rosaceae in relation to ecology, habit and phenology. IAWA Bull. new series 13(3):307349. 
